\title{
Study on the Ecological Urban Design in Hot Spring Resort
}

\author{
Luo Yubin \\ Department of Civil Engineering, Dongguan University of Technology, Dongguan, 523808, China \\ Rolandluo@163.com
}

Keywords: urban design, ecological theories, waterfront, resort

Abstract. This paper explains the application and development of ecological concept in urban construction. It takes the Hot Spring Resort urban design in Guangzhou Conghua city as an example to explain the process by comprehensive analysis of land ecological function, GIS Engineering, flood area and policy constraint evaluation to determine the planning area of mandatory reserve, restricted development zones and suitable construction areas. Under the principle of "ecological priority" it establishes the blue and green ecological network system and delineates three function structure and four levels of open space system.

\section{Introduction}

Urban design as a way to improve cities' space and physical environment has become an important part of urban planning. The application of ecological idea in urban design will make the city healthier so as to realize the sustainable development of the city.

This paper takes Guangzhou Conghua Liuxi hot spring resort urban design as an example and explores the ecological idea in urban design.

\section{Ecological theories application in urban design}

Urban Design means people organize the exterior space and physical environment of a city for a specific target of city construction. The building space and environment constructing by urban design format the city's art and life style and establish the quality and features of the city [1]. Urban ecosystem is not only a network structure interacted by urban society and nature but also an organic system of human established by human's adaptation, processing and transformation in nature [2]. City construction combined with nature originated in ancient times such as Chinese ancient "harmony between human and nature" and "Feng-Shui" theory.

Study on green space system during the industrial revolution. The industrial revolution promoted the city urbanization and social development. But at the same time it brings much city problems such as city crowded and deterioration of city environment as well as city sanitation etc. The scholars put forward to use green space to solve the city problems for the first time. For example Howard proposed the "Garden City" and Chicago "human ecological school" researched the city landscape and green space system.

Global environmental movement in 1960s. The global environmental movement erupted in the 1960s which prompt people to take a new look at the relationship between human and nature. The greatest impact is the USA ecologist I. L. McHarg. He wrote the book "Design with Nature" and proposed the concepts and methods of planning combining with ecology. He advocated reaching the nature characteristics in city and architecture and creating the environment for human survival [3].

China established the sustainable development as the basic national policy in 1990s.The United Nations held the conference on environment and development in 1992 with the global ecological concept and consensus formed. The Chinese governments established "sustainable development" as a basic national policy. In recent years, domestic scholars are beginning to use of ecological concept in urban design. For example, Wang Jianguo put forward the concept of "green urban design" and Yu Kongjian advocated the landscape ecological planning and design concept. It is now generally accepted that once we dealt with the natural and biological effects in the urban 
planning and urban design can we give our city spatial structure and unique form which will build a rich artistic charm of urban environment characteristics [4].

\section{Case study about ecological urban design in hot spring resort}

Project location. The planning area is located in the northeast of Guangzhou in Conghua city. The scope of urban design is the both sides of lands of Liuxi River and the total land area is 29.28 square kilometers. The planning area is rich in resources. The landscape spatial pattern is ridge valley and echelon distribution. The central district is the flat valley plain and ground. The southeast district is low mountains and the northwest district is hills which are lush vegetation. The planning area along the river flow is rich in hot spring transparent water. The hot spring is containing a variety of trace elements in minerals and precious fluoride ion and radon ion which is rare in the world of hot spring water. How to protect and rational use of the valuable ecological resources which in order to promote comprehensive development and tourism industry development of Conghua city is very important.

Suitability analysis of current situation of land. Due to the complex topography and many restricting factors of the planning area we take the ecology map superposition method in analysis of appropriate for the status of land.

We divided the planning area into ecological protection zone, ecological restoration area, ecological adjustment area, ecological economic zone through the evaluation of the utilization of land, vegetation, wildlife, water ecological resources etc. in the design. We would prohibit all construction and development activities and take some measures to strict water and water conservation in the ecological protection zone. We would implement the principle of adverse interference reduction in ecological restoration areas. The zone vegetation gradually restored to evergreen broad-leaved forest and riparian vegetation gradually improved. We would strengthen vigorously the ecological landscape function and improve the existing fruit planting structure in ecological adjustment zone. We should control reasonably the density and volume rate of the construction of ecological economic zone to retain the necessary public parks and open space.

We formulated the appropriate construction area and unsuitable construction area by analysis of the terrain elevation and slope through GIS technology. We determine the suitable construction area within 180 meters elevation through field investigation and present village distribution. According to the terrain slope of the engineering construction we design the area of less than $25 \%$ slope is suitable for construction and above $25 \%$ slope of the area is not suitable for construction.

There are three large rivers and many streams in the planning area. Both sides of the rivers are continuous mountains. So it is necessary to analyze the flood area due to flash floods may fall during the rainy season. We analyze 20 years and 50 years two possible case of flood inundation area.

According to the Guangzhou Conghua Hot Spring Health valley planning and Land Use Planning of Conghua Hot Spring we determined the protective belt of both sides of Liuxi River are within $100 \mathrm{~m}$. The land protection zone for river and basic farmland protection zone are the restricted development and construction land.

The above factors would be superimposed and the result would be the basis for the urban design of mandatory reserves zones, restricted development zones and the construction zones as shown in Fig.1. Any form of development and construction would be prohibited except for a small amount of hiking trails and riverside tourist trail in the compulsory reserve zones to protect forest vegetation and geomorphology. Restricted development zone was not suitable for construction except carry out moderate tourism development. According to urban planning land evaluation requirements the construction zone is divided into three types of land use to develop and construct. 


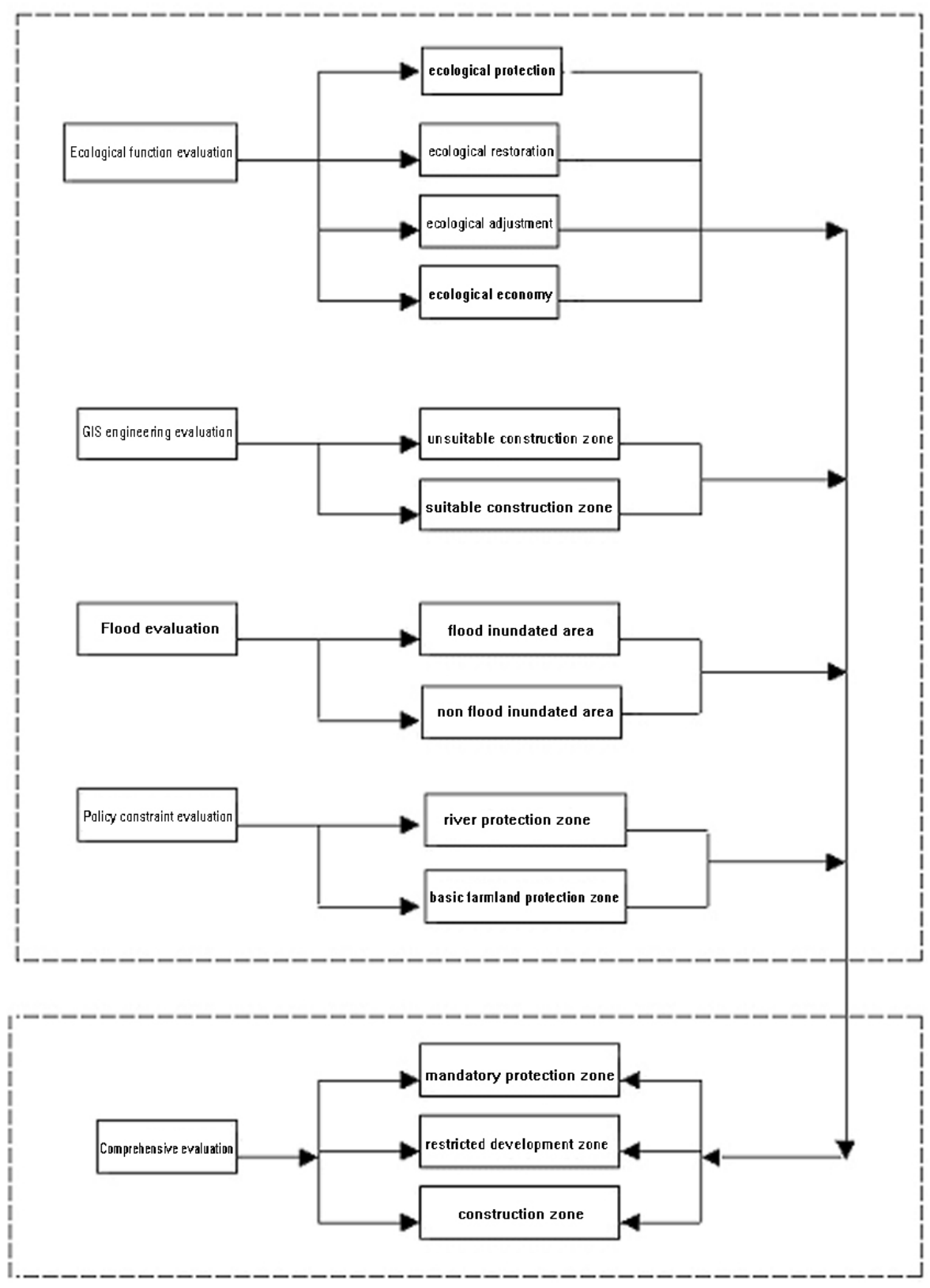

Fig.1 Sketch map of evaluating way

Structure of ecological priority. Based on the principle of "ecological priority" the ecological security pattern is the natural biological community. That is the natural patch, natural corridor and the natural basement are in the core and the dominant position [5]. We regard the planning area as a relatively complete ecosystem of vegetation patch and the river corridor. We protect and restore the natural ecological resources in the planning area and establish the ecological network of blue and green system as shown in Fig.2. The blue and green system should keep the natural texture space and form the core network system of natural landscape as well as create the sustainable utilization of resources. The ecological wetland park is built to degrade the dissolved pollution in the stream river corridor.

Taking the reasonable utilization of ecological resources and the hot water resources as the guidance the function of land planning is based on the land suitability evaluation combining the economic industrial structure of Conghua city as shown in Fig.3. Conference center, sports and ecological fruit land would be arranged in western business meeting area with economic industry in Conghua city. We set the industry exhibition showcases to promote the development of regional economy. The central hot spring health zone makes use of the precious hot spring water resources to promote the health of people in the district. 


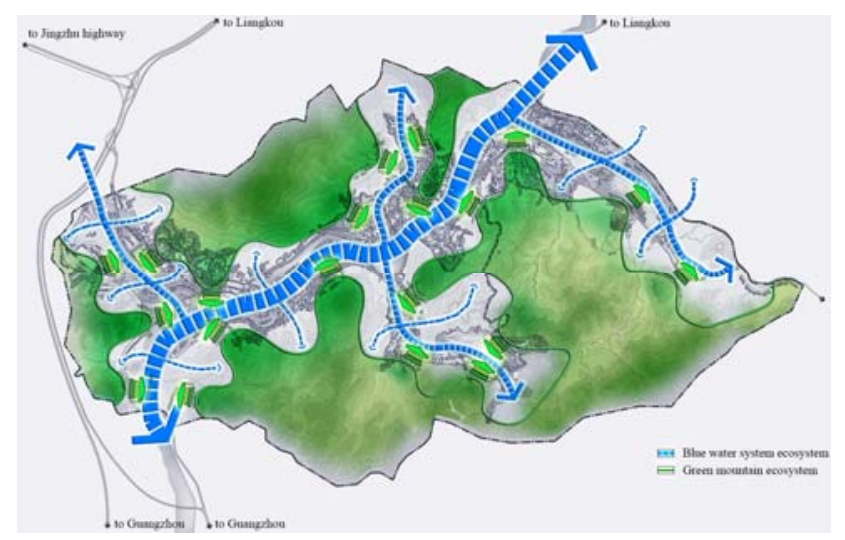

Fig.2 Blue and green ecosystem

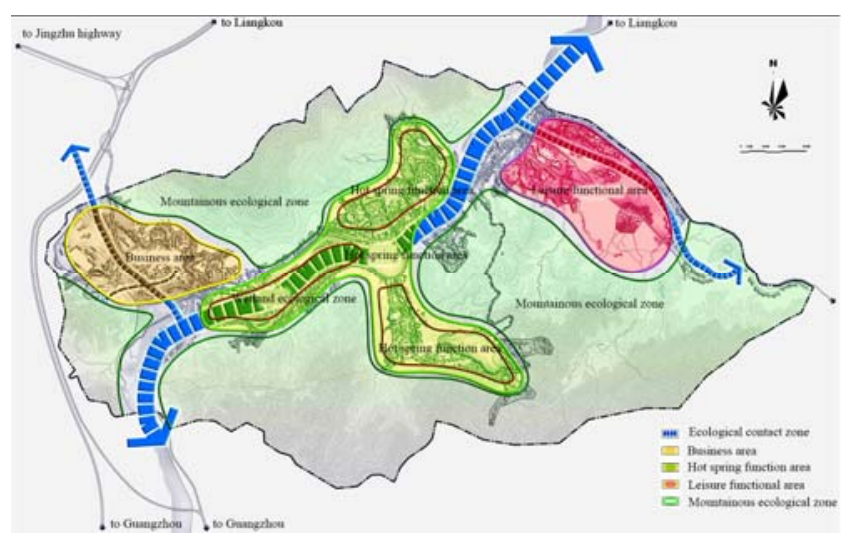

Fig.3 Function structure

Open space planning system. According to the blue and green network and function structure of the planning we developed a natural ecological open space system. The open space system is divided into 4 levels as shown in Fig.4 and Fig.5.

(1) Waterfront open space. We preserve the original ecology and through ridge vein in waterfront area to save the most basic public ecological landscape resources. Any construction activities are prohibiting in the district.

(2) Functional area. Each functional area is the connecting link to Waterfront open space of Liuxi river and communicate with the environment.

(3) Tour entrance space. The transition zone and the entrance space for the Functional area.

(4) Group open space. Many activities and exchanges occur in the group area.

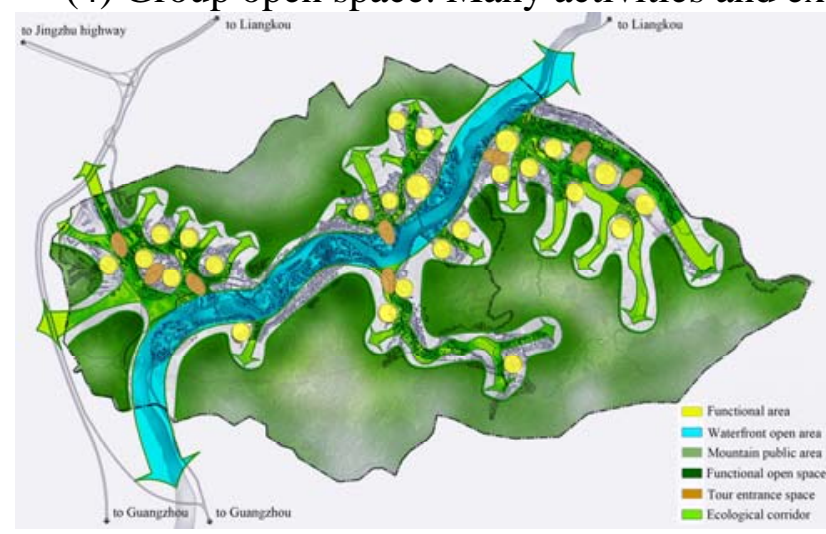

Fig.4 Open space analysis

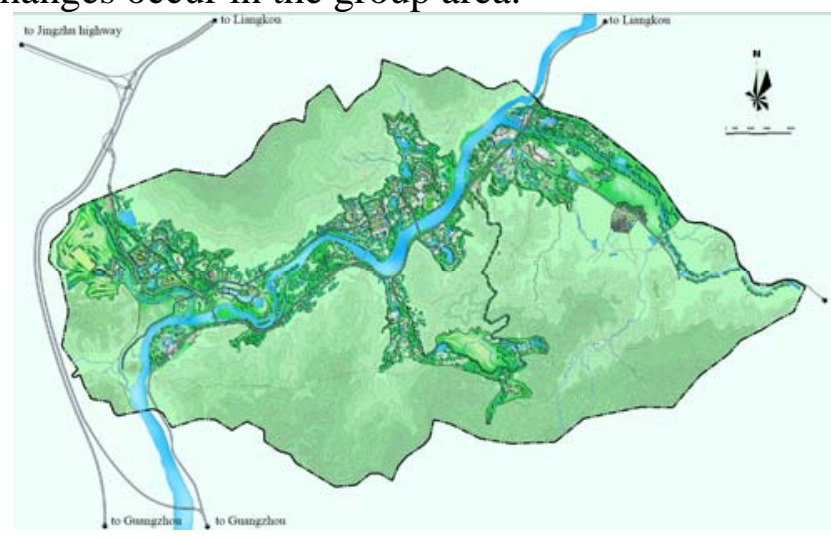

Fig.5 Master plan

\section{Summary}

Hot Spring Resort urban design in Guangzhou Conghua city embodies the idea of ecological planning by proposing reasonably land suitability evaluation and establishing city space form both with aesthetic value and conforms to the ecological benefit. Every inch of the land develops according with the law of ecology so as to promote the improvement of the whole environment and achieve the city's sustainable development.

\section{References}

[1] Jianguo Wang: Urban Design (Southeast University Press, Nanjing 1999).

[2] Yubin Luo: Applied Mechanics and Materials. Vol. 448-453 (2014), p. 4111-4114.

[3] I. L. McHarg: Design with Nature (China Architecture and Building Press, Beijing 1992).

[4] Jianguo Wang: Journal of Architecture. Vol.9 (1999), p. 20-23.

[5] Tao Zhou, Dexiang Li: Journal of Architecture. Vol.3 (2004), p. 18-21. 